\title{
Use of Spot Imagery for Estimating Surface Runoff in Sudan
}

\author{
*Abdullah S. Alsalman, \\ Box 800, Riyadh 11421, \\ Email: asalman@ksu.edu.sa
}

\begin{abstract}
Digital classification of remotely sensed data can be very effective in determining volume of runoff. Mean discrepancy value of $\pm 6 \mathrm{~mm}$ between observed and estimated runoff volume was obtained in this experiment with a standard deviation of $\pm 7.2 \mathrm{~mm}$.
\end{abstract}

\section{ملخص}

اثبت هذا البحث كفاعة وقوة المعالجة الرقدية لصور الاقمار الاصطناعية في دراسات تقدير حجم المباه السطحية

الجارية حيث امكن الحصول على قيم متبقيات (الفرق بين القيم الحقيقية والقيم الدقاسة) عن طريق الاستشعار عن بعد في

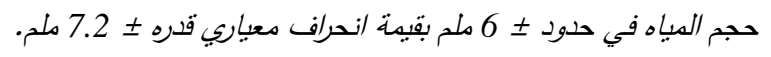

* College of Engineering, King Saud University 


\section{Introduction}

The design stage of large engineering projects such as irrigation schemes, highways, reservoirs, dams, irrigation canals, railways, etc., often requires voluminous and accurate information on various parameters. One of the most important parameters that need careful evaluation is the extent and significance of hydrological land use and land cover in the area concerned. This is because of the fact that quantity, quality and timing of runoff are strongly correlated with this parameter (Ali, 1989, Ostry, 1982). In this respect land use / land cover maps have been compiled and used extensively in the developed world to aid in the design process of such large engineering projects.

In many developing countries, however, such land use / land cover maps are either very poor or outdated or simply not available. Since reliable estimation of the quantity, rate and timing of runoff from ungauged watersheds (as experienced in many developing countries) is very difficult, the design and construction of a large engineering work in such an environment may face many problems because of lack of vital hydrologic information.

With the advent of satellite remote sensing, in particular the availability of high resolution imagery from sensors such as SPOT High Resolution Visible (HRV) push broom scanners, hydrologic scientists and engineers are now in a position enabling them to utilize this space data for the derivation of hydrologic information to be used as input to the design stage of engineering projects. This ability seems to have emerged from the success of the remote sensing techniques in other contiguous application areas such as agriculture, forestry, water management, land use mapping, flood monitoring and assessment, etc. Landsat Multispedral Scanner imagery has indeed been used in many occasions for deriving curve numbers on percentage basis for extensive catchment' areas. This was accomplished by correlating the well-known Department of Agriculture (USA) Soil Conservation Service (USA) (SCS) curve numbers with hydrologic soil groups (Slack and Welch, 1980, Ragan and Jackson, 1980).

The purpose of this paper is to report results of a pilot experiment concerned with a similar investigation. However, SPOT push broom scanner imagery was used instead of Landsat data. A land use / land cover map was 
first prepared of Khor Abu Habil stream river basin area in central Sudan. This is a necessary step in such hydrological studies (Ragan and Jackson, 1990). A hydrological model was then developed from SPOT images for the prediction of total runoff with the help of the SCS curve number method.

\section{Test Area, Martial and Procedure}

Khor Abu Habil is a seasonal river in Central Sudan (Fig.1) . It originates from the Nuba Highlands in Kordofan Province, traverses north for some $100 \mathrm{~km}$ and then diverts gently to the east-north to meet the main White Nile at the small town of Ash-Shour.

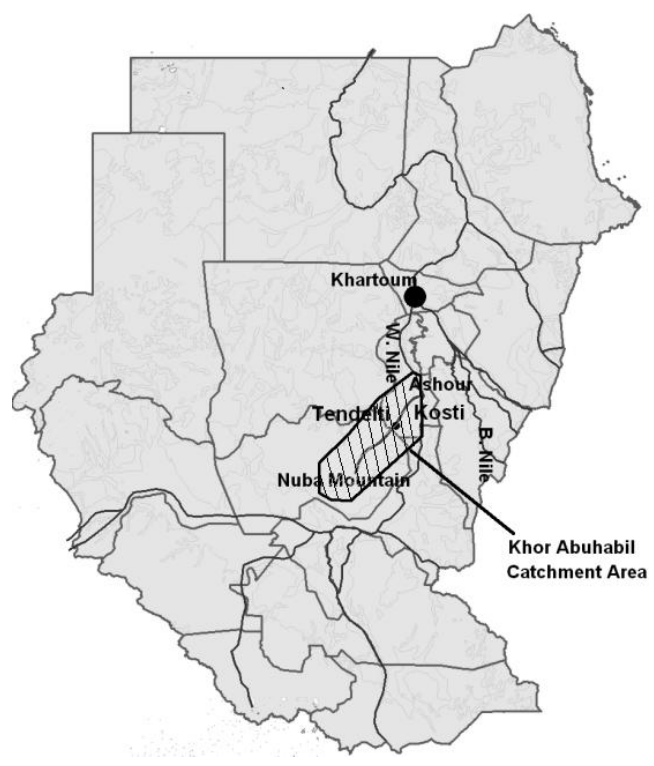

Figure (1): Location of Test Area

The length of the river is about $350 \mathrm{~km}$ and its basin consists mainly of composed alluvial soil with some white sand sometimes involved. The topography has a gentle slope towards the north and north-east (Figure 2). The average annual rainfall is about $200 \mathrm{~mm}$. 


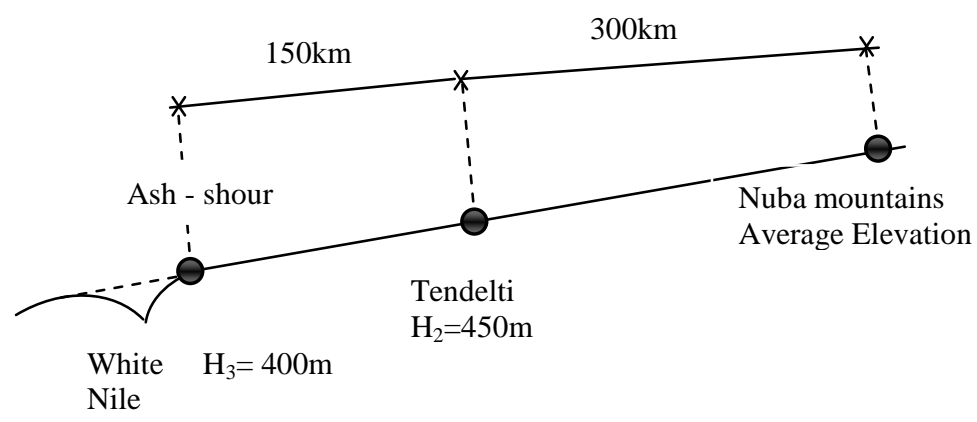

\section{Figure (2): A longitudinal Section of Khor Abu Habil Facing North / North East.}

Imagery used in this experiment consists of SPOT-2 multispectral (XS1, XS2, XS3) images on computer-compatible tapes, taken in July/August 1998(Figure 3).

The scale of the imagery was about $1 / 100000$. Originally, the imagery was utilized for digital classification of land and water resources mapping in the test area. The process of digital classification was carried out at the National Remote Sensing Center in Khartoum using an ERDAS version 8.0 software package. Only three scenes of the test area were used in the experiment. The three scenes were read in the computer disk, to facilitate fast processing, through the input device of the image workstation. The contents of the image were classified using the technique of supervised classification. The outcome of the digital classification process was then manually examined and subsequently digitally merged and the river basin was split. A land use map was then compiled at a scale of $1 / 100000$ (Figure 4). This scale was believed to be appropriate for such hydrologic studies (Ali, 1989). 


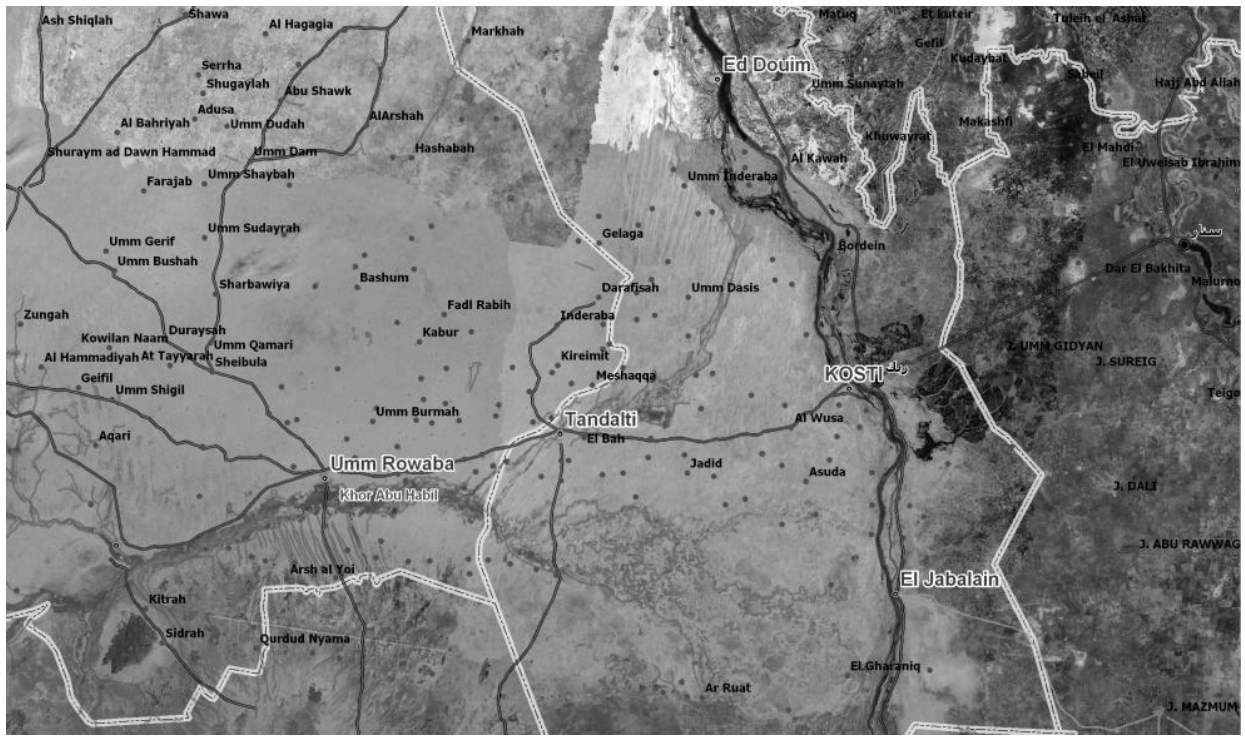

Figure (3): Multispectral (XS1, XS2, XS3) Images on

Computer-Compatible Tapes

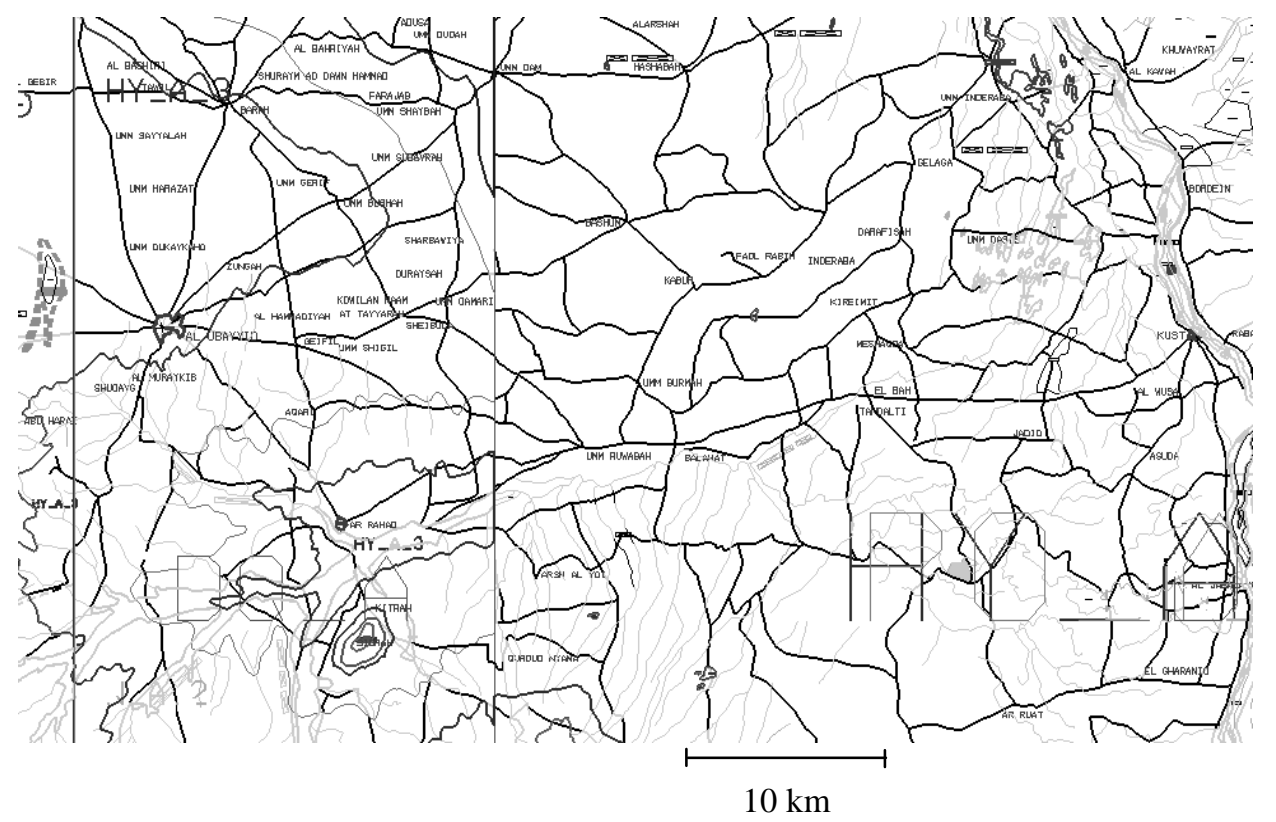

Figure (4): A Land Use / Land Cover Map of Part of the Test Area. 


\section{USDA SCS and Hydrologic Model Development}

Hydrologic model derived from the SCS curve numbers encompasses correlations between hydrologic soil class, land cover and curve number. The curve number represents the runoff potential of the hydrologic soil cover complexes.

According to Tiwari et al (1991), for small watersheds the SCS runoff model is given by:

$\mathrm{Q}=(\mathrm{P}-0.2 \mathrm{~S})^{2} /(\mathrm{P}+0.8 \mathrm{~S})$

Where $\mathrm{Q}=$ actual runoff $(\mathrm{cm})$;

$\mathrm{P}=$ total rainfall $(\mathrm{cm})$;

$\mathrm{S}=\left(1000 / \mathrm{C}_{\mathrm{n}}\right)-10$, and

$\mathrm{C}_{\mathrm{n}}=$ curve number which is a function of soil type, land use/land cover, vegetation cover and moisture condition.

Murtada (1988) modified equation (1) to represent the environment of Central Sudan as follows:

$\mathrm{Q}=(\mathrm{P}-0.15 \mathrm{~S})^{2} /(\mathrm{P}+0.6 \mathrm{~S})$, and

$\mathrm{S}=83\left\{\left(1000 / \mathrm{C}_{\mathrm{n}}\right)-1\right\}$

\section{Curve Number Determination from Satellite Digital Data}

Since, in general, land use / land cover information obtained from satellite data is much more general, a curve-number classification system compatible with satellite data had to be established. This was carried out using the SCS Table values of runoff curve numbers and equation (2). Examination of the table reveals that for agriculture, for example, the values of the curve number is the arithmetic mean under the headings of straight row, contoured, and terraced and bounded conditions. Other factors involved include moisture condition, hydrologic soil cover and hydrologic soil groups.

Of course, the image had to be subdivided into sub-basins whose express curve numbers had to be computed. Further, for each sub-basin, a 
weighted value of curve number $\mathrm{C}_{\mathrm{w}}$ had to be computed using the standard formula:

$$
C_{w}=\frac{\sum_{i=1}^{n} C_{n i} A_{i}}{\sum_{i=1}^{n} A_{i}}
$$

Where $\mathrm{C}_{\mathrm{ni}}$ are the curve numbers for the various land uses and hydrologic groups in the sub-basin; and $\mathrm{A}_{\mathrm{i}}$ are the respective sub-basin areas.

It follows that the effective curve number $\mathrm{C}_{\mathrm{e}}$ for the whole basin can be computed from a modified version of equation (3), thus:

$$
C_{e}=\frac{\sum_{j=i}^{n} C_{w j} A_{j}}{A_{T}}
$$

Where $\mathrm{C}_{\mathrm{wj}}$ are the curve numbers for sub-basin $\mathrm{j}$, and $\mathrm{A}_{\mathrm{T}}$ is the total area of watershed.

\section{Computations, Results and Analysis}

In order to compare the predicted and measured volume of runoff, the following mathematical algorithm was used:

$\Delta Q_{m}=K_{m p} \Delta Q_{P}$

Where $\Delta \mathrm{Q}_{\mathrm{m}}=$ measured volume of runoff - mean of observed volume of runoff $\left(\mathrm{Q}_{1}-\mathrm{Q}_{1}\right)$,

$\triangle \mathrm{Q}_{\mathrm{P}}=$ predicted volume of runoff - mean of predicted volume of runoff $\left(\mathrm{Q}_{2}-\right.$ $\mathrm{Q}_{2}$ ), and:

$\mathrm{K}_{\mathrm{mp}}=$ regression coefficient of $\mathrm{Q}_{1}$ on $\mathrm{Q}_{2}$ 


$$
=\frac{\left[\sum Q_{1} \sum Q_{2}-n \sum Q_{1} Q_{2}\right]}{\left[\left(\sum Q_{2}\right)^{2}-n \sum Q_{2}^{2}\right]}
$$

The area of the basin was computed and found to be $715 \mathrm{~km}^{2}$. The digital interpretation stage of the experiment using SPOT imagery gave the land use classes shown on Table (1).

Table (1): Land Use Classes on the Basin

\begin{tabular}{|c|c|}
\hline$\%$ area & Land use type \\
\hline 38 & Open forest \\
\hline 20 & Bare land \\
\hline 2 & Settlement \\
\hline 35 & Agriculture \\
\hline 2 & Water bodies \\
\hline 3 & Unclassified \\
\hline
\end{tabular}

The curve numbers for the various land use classes and hydrologic soil groups were then computed via a FORTRAN computer program (MORUN) and used to derive the value of $\mathrm{C}_{\mathrm{e}}$ according to equation (3). The value of $\mathrm{C}_{\mathrm{e}}$ was found to be 0.68 . This value was used as input in order to determine the volume of runoff for four storms that happened during July/August 1998. The actual mean discharge information of the four storms was collected from local gauging stations. This latter was used to derive actual measured (or observed) volume of runoff by drawing hydrographs and separating base-flows from the values of each storm runoff (in this experiment base-flows were not significant). Table (2) shows a comparison of the measured and estimated values of volume runoff for Abu Habil basin.

Table (2) Comparison of Measured and Observed Volume of Runoff for the Four Storms

\begin{tabular}{|c|c|c|c|}
\hline Discrepancy (mm) & $\begin{array}{c}\text { Estimated Runoff } \\
(\mathbf{m m})\end{array}$ & $\begin{array}{c}\text { Actual Runoff } \\
(\mathbf{m m})\end{array}$ & $\begin{array}{c}\text { Storm } \\
\text { No. }\end{array}$ \\
\hline+8.7 & 21.9 & 30.6 & 1 \\
\hline+5.5 & 31.4 & 36.9 & 2 \\
\hline-3.6 & 20.5 & 16.9 & 3 \\
\hline+6.1 & 16.7 & 22.8 & 4 \\
\hline
\end{tabular}


From Table (2), it can be seen that an average absolute deviation of 6 $\mathrm{mm}$ had been obtained in this experiment with a standard deviation of $\pm 7.2 \mathrm{~mm}$.

The measured volume of runoff and its estimated equivalent were used as input to a linear regression computer program in order to determine the regression coefficient of the first (volume of runoff) on the second (the estimated equivalent). The coefficient was found to be 0.91 .

Taking all these findings into consideration, it is evident that remote sensing techniques can be used effectively in estimating volume of runoff. This is an important conclusion for developing countries where stream- gauging stations are usually old, malfunctioning or not available at all.

\section{Conclusions}

The test was initiated in order to investigate the possibility of using remote sensing digital image processing techniques in establishing volumes of runoff in developing countries. The USDA SCS tables (modified for the Sudanese environment) were used to establish curve numbers, which were utilized to compute volume of runoff. This was compared with the actual values. The average deviation was found to be $6 \mathrm{~mm}$ with a standard deviation of $\pm 7.2 \mathrm{~mm}$ and a linear regression coefficient of 0.91 . This shows that digital image processing techniques of SPOT remotely sensed data are capable of producing high accuracy figures in determining volume of runoff. This is an important conclusion for developing countries where stream gauging stations are not working properly or simply not available.

\section{Acknowledgment}

The author would like to express his gratitude to professor Abdullah Elsadig Ali , Surveyor General of Sudan who kindly supplied the data and the material used in this paper. Mr. Engineer M. Bilal wrote the computer programme used in the calculations of volume of runoff. My sincere thanks are due to both of them. 


\section{References}

1- Ali, A.E. (1989), "Assessment of Visual Interpretation of Thematic Mapper (TM) Images for Land Use and Cover in Sudan," Earth Surface Processes and Landforms, Vol. 14, pp. 399-405.

2- Murtada, M. (1988), "Modification of the SCS Runoff Model to Suit a Savanna Environment "Bildmessung und Luftbildwesen, Vol. 44, pp.35-41 (in German).

3- Osry, R.C. (1982), "Relationship of Water Quality and Pollutant Loads to Land Use in Adjoining Watersheds, "AWRA Water Resources Bulletin, Vol. 18, pp.99-104.

4- Ragan, R.M. and Jackson, T.J., (1990), "Runoff Synthesis Using Landsat SCS Model." Journal of Hydraulic Division, ASCE Vol. 106, pp. 667-678.

5- Slack, R.B. and Welch, R, (1980). "Soil Conservation Service Runoff Curve Number Estimates from Landsat Data, "Water Resources Bulletin, Vol 16, No.5, pp .887-893.

6- Tiwari K.N. Kumar, P, Sebastian, M. and Pal, D. K. (1991) Hydrologic Modeling for Runoff Determination, "Water Resources Development, Vol. 7, No, 3. PP. 178.184. 